\title{
Chemokine receptor CXCR4 expression, function, and clinical implications in gastric cancer
}

\author{
HYO JIN LEE ${ }^{1}$, SEONG WOO KIM ${ }^{1}$, HA YON KIM ${ }^{1}$, SHENGJIN LI ${ }^{2}$, HWAN JUNG YUN ${ }^{1}$, \\ KYU SANG SONG ${ }^{2}$, SAMYONG KIM ${ }^{1}$ and DEOG YEON JO ${ }^{1}$ \\ Departments of ${ }^{1}$ Internal Medicine and ${ }^{2}$ Pathology, Cancer Research Institute, Daejeon Regional Cancer Center, \\ Chungnam National University College of Medicine, Daejeon, Korea
}

Received July 2, 2008; Accepted November 7, 2008

DOI: 10.3892/ijo_00000172

\begin{abstract}
The chemokine receptor CXCR4 is associated with the biological behavior of cancer, but few studies have addressed the expression and function of CXCR4 in human gastric cancer and its impact on disease prognosis. We studied the expression of CXCR4 using RT-PCR, Western blotting, flow cytometry, and confocal microscopy in five gastric cancer cell lines. We also examined cell proliferation, migration, and anti-apoptotic activity in response to stromal cell-derived factor (SDF)- $1 \alpha$ and evaluated SDF-1 $\alpha /$ CXCR 4 signaling pathways. Furthermore, we investigated the correlation between CXCR 4 expression and the clinical features of 221 gastric cancer tissue samples. CXCR4 transcripts and proteins were detectable in all five gastric cancer cell lines. However, MKN-28, MKN-45, MKN-74, and SNU16 cells did not express membrane CXCR4. In contrast, KATO III cells expressed membrane CXCR4. In these cells, SDF-1 $\alpha$-induced migration was observed and was blocked by AMD3100, a specific inhibitor of CXCR4. SDF- $1 \alpha$ induced rapid phosphorylation of Erk1/2 MAPK but did not promote phosphorylation of Stat3 or Akt. Gastric cancer tissue samples expressed CXCR4 with variable intensities. Strong CXCR4 expression was significantly associated with lymph node metastases $(\mathrm{P}=0.028)$ and higher stages III/IV $(\mathrm{P}=0.047)$, and further tended to be correlated with a reduced 5-year survival rate ( $42.6 \%$ vs. $53.9 \%$; $\mathrm{P}=0.1)$. In conclusion, $\mathrm{CXCR} 4$ expression is associated with gastric cancer cell migration in vitro, and strong expression of CXCR4 by gastric cancer cells is significantly associated with lymphatic metastasis in patients with gastric cancer, suggesting that CXCR4 plays an important role during gastric cancer progression.
\end{abstract}

Correspondence to: Professor Deog Yeon Jo, Department of Internal Medicine, Chungnam National University Hospital, 640 Daesa-dong, Jung-gu, Daejeon, Korea

E-mail: ggufwhd@naver.com

Key words: CXCR4, gastric cancer, prognosis, SDF-1

\section{Introduction}

Chemokines are a superfamily of small structurally related chemoattractant cytokines that are essential for lymphocyte trafficking and maintenance of immune function $(1,2)$. Chemokines also affect angiogenesis, collagen production, B-cell lymphopoiesis, and bone marrow myelopoiesis $(3,4)$. The interaction of these chemokines with their specific seven-transmembrane G-protein-coupled receptors mediates their biological effects. Based on the position of the first two conserved cysteines, the chemokines are classified into four subfamilies, CXC, CC, C, and CX3C. More than 40 chemokines and 18 chemokine receptors have been identified in humans $(2,5)$.

Recent data indicate that certain chemokines and their receptors, in particular stromal cell-derived factor (SDF)- $1 \alpha$ and CXC chemokine receptor 4 (CXCR4), play a critical role in the behavior of cancer cells and modulate cell migration, proliferation, and survival. SDF-1 $\alpha$ and its unique receptor CXCR4 are expressed in various epithelial cancer cells and are associated with tumor biology (5-7). For example, Muller et al showed that the chemokine receptor CXCR4 was highly expressed in human breast cancer cells and that activation of breast cancer cells with SDF-1 $\alpha$ induced chemotaxis and tissue invasion in vitro (8). In addition, they showed that neutralizing the interaction of SDF- $1 \alpha$ and CXCR4 significantly impaired metastasis of breast cancer cells to regional lymph nodes and lung in vivo, suggesting that chemokines and their receptors have a critical role in determining the metastatic destination of tumor cells (8). CXCR4 has also been implicated in the progression of pancreatic cancer, small cell lung cancer, glioblastoma, and bladder cancer (4,9-11).

Nevertheless, few studies have addressed the expression and function of CXCR4 in human gastric cancer, and the impact of CXCR4 on disease progression and prognosis is unknown. Therefore, we investigated the expression and function of CXCR4 in gastric cancer cell lines and attempted to clarify the clinical implications of CXCR4 expression in gastric cancer.

\section{Materials and methods}

Cell culture. Five human gastric cancer cell lines and RPMI8226 myeloma cells were used in this study. MKN-28, 
MKN-45, MKN-74, KATO III, and SNU-16 were obtained from the Korean Cell Line Bank (Seoul, Korea). RPMI-8226 cells were purchased from the American Type Culture Collection (Manassas, VA). The cells were cultured in RPMI-1640 (Gibco BRL Life Technologies, Grand Island, NY) supplemented with $10 \%$ fetal bovine serum (FBS; Gibco BRL Life Technologies), $100 \mathrm{U} / \mathrm{ml}$ penicillin $\mathrm{G}, 100 \mu \mathrm{g} / \mathrm{ml}$ streptomycin (Sigma Chemical Co., St. Louis, MO) and $1 \mathrm{mmol} / 1 \mathrm{~L}-$ glutamine (Gibco BRL Life Technologies) at $37^{\circ} \mathrm{C}$ and $5 \%$ $\mathrm{CO}_{2}$.

Cytokine and reagent. SDF-1 $\alpha$ (purchased from R\&D Systems, Inc., Minneapolis, MN) and AMD3100 (Sigma Chemical Co.) were used.

RNA isolation and semiquantitative reverse transcription$P C R$. Total RNA was prepared from the cells with TRIzol reagent (Gibco BRL Life Technologies) according to the manufacturer's instructions. After purification, $1 \mu \mathrm{g}$ of RNA was reverse-transcribed with SuperScript reverse transcriptase (Gibco BRL Life Technologies) and the universal primer oligo dT15 (Promega, Madison, WI). One microliter of the cDNA was used as a template for the specific PCR reactions. The following primers were used: human CXCR4 (sense, AAT CTT CCT GCC CAC CAT CTA CTC C; antisense, GCG GTC ACA GAT ATA TCT GTC ATC TGC C); GAPDH (sense, GAG TCA ACG GAT TTG GTC GTA; antisense, AGT TGT CAT GGA TGA CCT TGG). For amplification, a GeneAmp PCR system (Perkin-Elmer, Norwalk, CT) thermocycler was used. Cycling conditions of the respective PCRs were as follows: denaturation $\left(1 \mathrm{~min}\right.$ at $\left.94^{\circ} \mathrm{C}\right)$ followed by the respective number of cycles $(1 \mathrm{~min}$; GAPDH, 28 at $60^{\circ} \mathrm{C}$; CXCR 4,35 at $\left.62^{\circ} \mathrm{C}\right)$ of annealing and elongation $(1 \mathrm{~min}$ at $\left.72^{\circ} \mathrm{C}\right)$. After the last cycle, a final extension $(10 \mathrm{~min}$ at $72^{\circ} \mathrm{C}$ ) was added, and thereafter the samples were kept at $4^{\circ} \mathrm{C}$. Fifteen microliters of the products were run on a $1.8 \%$ agarose gel, stained by ethidium bromide, and visualized under UV light. RPMI-8226 cells were used as a positive control for CXCR4.

Western blot analysis. Western blotting was used to detect CXCR4 protein and the phosphorylation of signaling molecules. The cells were collected by centrifugation, washed in phosphate-buffered saline (PBS), and lysed by the addition of SDS sample buffer [62.5 mM Tris- $\mathrm{HCl}(\mathrm{pH} 6.8), 6 \%(\mathrm{w} / \mathrm{v})$ SDS, 30\% glycerol, $125 \mathrm{mM} \mathrm{DTT}$, and $0.03 \%(\mathrm{w} / \mathrm{v})$ bromophenol blue]. The whole cell samples were sonicated, lysed, and denatured by boiling for $5 \mathrm{~min}$. Equal amounts of protein from each sample were electrophoresed on $10 \%$ SDS-polyacrylamide gels and transferred to nitrocellulose membranes. The membranes were blocked for $1 \mathrm{~h}$ with Tris-buffered saline (TBS) containing 5\% (w/v) milk and $0.1 \%$ Tween, and then incubated with the primary antibody overnight at $4^{\circ} \mathrm{C}$. The blots were washed with TBS containing Tween, incubated with the appropriate secondary antibody (Cell Signaling Technology, Inc., Boston, MA) for $2 \mathrm{~h}$, and developed using West-Zol Plus (iNtRON Biotechnology, Seoul, Korea). For phosphorylation studies, the cells were starved in serum-free medium for $12 \mathrm{~h}$ and then stimulated with cytokines. The following antibodies were used: anti-
CXCR4 monoclonal antibody (12G5; R\&D Systems, Inc.), anti-phospho-AKT polyclonal antibody (S473), anti-AKT polyclonal antibody, anti-phospho-ERK polyclonal antibody (T202, Y204), anti-ERK polyclonal antibody, anti-phosphoStat3 polyclonal antibody (T705), anti-Stat3 polyclonal antibody (all purchased from Cell Signaling Technology, Inc.).

Flow cytometry. Cells were incubated with phycoerythrin (PE)-conjugated monoclonal antibodies at $4{ }^{\circ} \mathrm{C}$ for $30 \mathrm{~min}$ and were analyzed using a Coulter Elite flow cytometer (Coulter Electronics Ltd., Hialeah, FL). The monoclonal antibodies used in the study were PE-conjugated anti-CXCR4 (12G5; R\&D Systems, Inc.). To detect cytoplasmic CXCR4, the cells were permeabilized with saponin-based reagents (BD Pharmingen, San Diego, CA) before labeling. Isotype mouse IgG1 (Becton-Dickinson, Franklin Lakes, NJ) was used as a control. Serum deprivation-induced cell apoptosis was detected by staining cells with fluorescein isothiocyanate (FITC)-conjugated annexin V and propidium iodide (PI; BD Pharmingen) according to the manufacturer's instructions and were subsequently analyzed by flow cytometry.

Laser confocal microscopy. Cells were washed three times with cold PBS and fixed in $3.7 \%$ formaldehyde for $30 \mathrm{~min}$. Cells mounted on glass slides were permeabilized with $2 \mathrm{ml}$ of PBS containing $0.1 \%$ Triton $\mathrm{X}-100$ and $0.1 \mathrm{M}$ glycine at room temperature. After 15-min incubation, the cells were washed three times with $1 \mathrm{X}$ PBS and blocked with $3 \%$ bovine serum albumin (BSA) in PBS for 10 min at room temperature. Cells were incubated with primary anti-CXCR4 antibody for $1 \mathrm{~h}$ at $37^{\circ} \mathrm{C}$, washed three times with $1 \mathrm{X}$ PBS, and incubated for $1 \mathrm{~h}$ at $37^{\circ} \mathrm{C}$ with FITC-conjugated anti-mouse and rhodamine-conjugated anti-rabbit secondary antibodies (Jackson ImmunoResearch Laboratories, Inc., West Grove, PA). The cells were then mounted on glass slides and observed under a laser-scanning confocal microscope (Olympus Corp., Tokyo, Japan).

Proliferation assay. MKN-28, MKN-45, MKN-74, KATO III, and SNU-16 cells $\left(5 \times 10^{4}\right.$ cells per well) were plated in a 96-well plate for the indicated times in $100 \mu \mathrm{l}$ RPMI-1640 with $10 \% \mathrm{FBS}$ or without serum. The cells were then stimulated with $100 \mathrm{ng} / \mathrm{ml} \mathrm{SDF}-1 \alpha$ for the indicated periods of time or were left untreated. To determine cell viability, we used the Cell Counting Kit-8 (Dojindo Molecular Technologies, Inc., Gaithersburg, MD) according to the manufacturer's instructions.

Cell migration assay. Migration of each cell type used in the experiments was assessed in 24-well chemotaxis chambers. Briefly, cells $\left(2.5 \times 10^{5}\right.$ cells/well resuspended in serum-free RPMI-1640 media) were loaded into the upper chamber of a Transwell ${ }^{\circledR}$ plate containing a $4-\mu \mathrm{m}$ microporous membrane (Corning Inc., Corning, NY) and were allowed to migrate into the lower chamber, which contained different concentrations of SDF- $1 \alpha$ or media alone (resuspended in serum-free RPMI-1640 media) for $4 \mathrm{~h}$. The migrated cells were counted under light microscopy and expressed as the numbers of cells migrated per high-power field (HPF). 
A
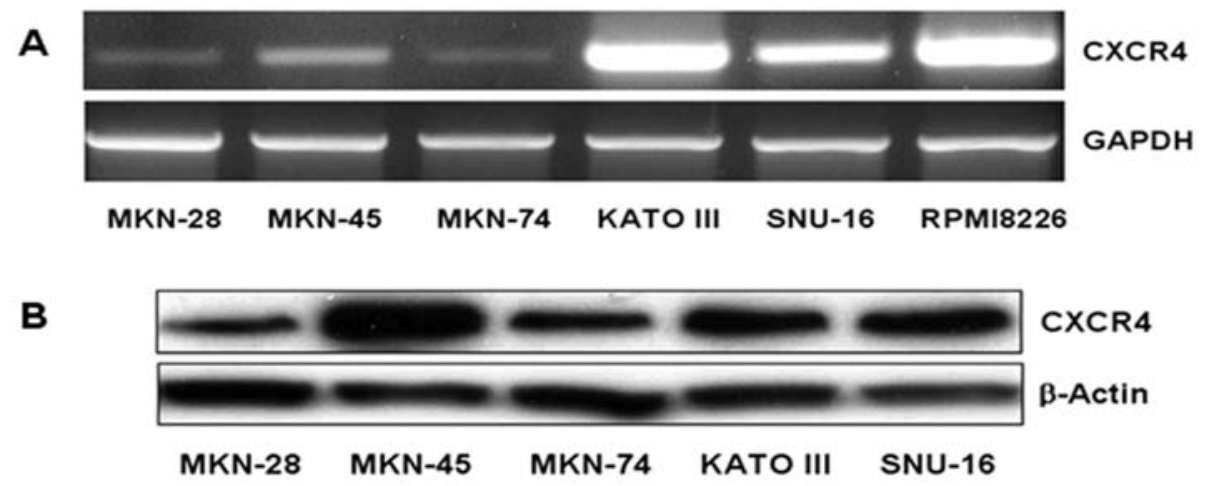

C
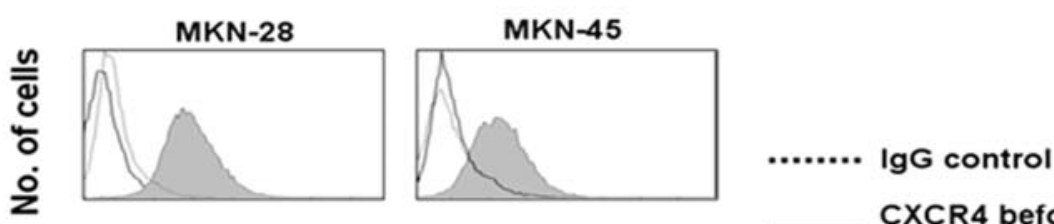

MKN-74

SNU-16
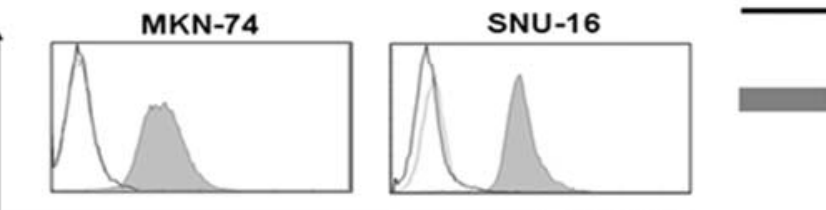

CXCR4 before permeabilization

CXCR4 after permeabilization

D

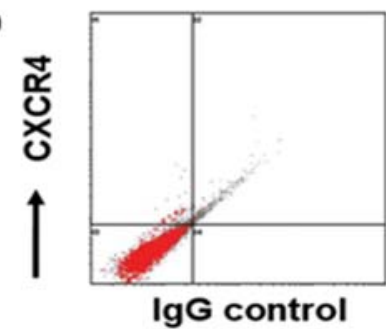

IgG control

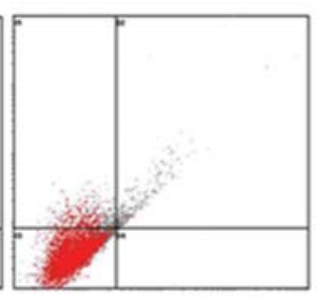

$12 \mathrm{G5}$
E

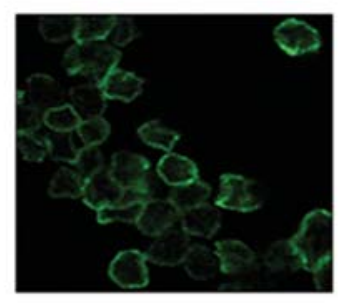

KATO III

Figure 1. Expression of CXCR4 in cancer cells. A, MKN-28, MKN-45, MKN-74, KATO III, SNU-16, and RPMI-8226 cells were cultured to 80\% confluence in 6-well plates, and total cellular RNA was isolated. CXCR4 transcript levels were measured by RT-PCR. B, MKN-28, MKN-45, MKN-74, KATO III, and SNU-16 cells were cultured to 50\% confluence in RPMI-1640 medium with $10 \%$ serum. Total cell lysates were prepared and analyzed by Western blotting with the anti-CXCR4 antibody. C, Flow cytometric analysis of MKN-28, MKN-45, MKN-74, and SNU-16 cells. Cell surface expression of CXCR4 was analyzed using anti-CXCR4 antibodies (12G5). Abundant CXCR4 was detected only in the cytoplasm of the cells after permeabilization. D and E, Flow cytometric and laser confocal microscopic analyses of KATO III cells, respectively. A small population of KATO III cells expressed membrane CXCR4. Data are representative of at least three independent experiments.

Tissue samples. Gastric cancer tissue samples were obtained from 221 consecutive patients undergoing elective surgery for gastric cancer at the Chungnam National University Hospital between 2000 and 2003. The patients had histologically confirmed adenocarcinomas of the stomach. All patients signed informed consent for therapy as well as for subsequent tissue studies, which had received prior approval by the institutional review board. The patients underwent $\mathrm{R} 0$ resection with at least D1 lymph node dissection. The clinocopathological features were assessed by the general rules of the Japanese Gastric Cancer Association (12).

Immunohistochemical staining of CXCR4 in gastric cancer tissues. Immunohistochemical staining was performed using the EnVision-HRP detection system (DakoCytomation, Inc., Carpinteria, CA) and anti-CXCR4 antibodies (MAB172; R\&D Systems, Inc.) according to the manufacturer's protocols.
Sections ( $3 \mu \mathrm{m})$ were cut from gastric cancer tissue microarray blocks, mounted on slides treated with APES (Sigma Chemical Co.), and dried for $1-2 \mathrm{~h}$ at $56^{\circ} \mathrm{C}$ before staining. Briefly, the sections were deparaffinized in xylene and rehydrated in graded alcohol. After antigen retrieval by heating in a pressure cooker in $1 \mathrm{mM}$ ethylenediaminetetraacetic acid (EDTA; pH 8.0) at full power for 4 min, tissue sections were treated with $3 \%$ hydrogen peroxide for $10 \mathrm{~min}$ to block endogenous peroxidases. The sections were then incubated overnight in a humid chamber at $4{ }^{\circ} \mathrm{C}$ with anti-CXCR 4 antibody (1:200) diluted with background reducing diluent (S3022; DakoCytomation, Inc.). Slides were then incubated with Envision reagent for $30 \mathrm{~min}$ followed by 3,3'-diaminobenzidine (DAB) chromogen for $5 \mathrm{~min}$, counterstained with Mayer's hematoxylin, and mounted. Exclusion of the primary antibody during immunostaining was used as a negative control, while spleen sections served as a positive control. Positive 
immunostaining was evaluated by two independent authors (S. Li and G.S. Song) who were blinded to patient outcomes and clinicopathological findings. The immunohistochemical staining was categorized according to a scoring method; tumors were classified into four grades based on the staining intensity (score 0, no staining intensity; score 1, weak staining intensity; score 2, intermediate staining intensity; score 3, strong staining intensity). In the case of heterogeneous staining within the samples, the respective higher score was chosen if $>50 \%$ of the cells showed higher staining intensity. The relative expression of CXCR4 was indicated by its staining intensity (i.e., strong staining indictated high CXCR4 expression and others indicated low CXCR4 expression).

Statistical analysis. The association of CXCR4 expression with clinicopathologic features was assessed using $\chi^{2}$ test and paired Student's t-test. Survival rates were visualized by applying Kaplan-Meier curves, and P-values were determined by the log-rank test, with $\mathrm{P}<0.05$ considered significant. All statistical analyses were conducted using SPSS 13.0 (SPSS Inc., Chicago, IL).

\section{Results}

CXCR4 expression in gastric cancer cell lines. We examined the expression of CXCR4 in five gastric cancer cell lines (MKN-28, MKN-45, MKN-74, KATO III, and SNU-16). CXCR4 transcripts and proteins were detectable by RT-PCR and Western blot analysis, respectively, in all five cell lines (Fig. 1A and B). After identifying CXCR4 transcripts and proteins, we analyzed the membrane expression of CXCR4 in the cell lines using flow cytometry and confocal microscopy. MKN-28, MKN-45, MKN-74, and SNU-16 cells did not express membrane CXCR4, but had abundant CXCR4 in their cytoplasm (Fig. 1C). In contrast, a small population of KATO III cells $(4.0 \pm 0.3 \%)$ expressed membrane CXCR4 (Fig. 1D and E). These findings suggest that membrane expression of CXCR4 is not always correlated with CXCR4 transcripts and/or proteins in gastric cancer cells.

Functional role of CXCR4 in gastric cancer cells. We first examined SDF- $1 \alpha$-induced migration, proliferation, and survival in CXCR4-containing cells. As expected, MKN-28, MKN-45, MKN-74, and SNU-16 cells, which did not express membrane CXCR4, showed no biological response upon challenge with SDF-1 $\alpha$ (Figs. 2 and 3A). KATO III cells, which expressed membrane CXCR4 on their cell surface, did not show proliferation or anti-apoptotic activity in response to SDF-1 $\alpha$ treatment; however, the cells migrated toward a SDF- $1 \alpha$ gradient (Figs. 2 and 3A). Furthermore, SDF- $1 \alpha-$ induced migration of KATO III cells was dose-dependent, and was blocked by AMD3100, a small molecule that specifically inhibits the CXCR4 receptor (Fig. 3B). These data suggest the presence of functional membrane CXCR4 in KATO III cells, which could play a role in cancer cell migration.

SDF-1a/CXCR4 stimulates mitogen-activated protein kinases (MAPK) in KATO III cells. Because membrane CXCR4 in KATO III cells was shown to transduce migratory responses,
A

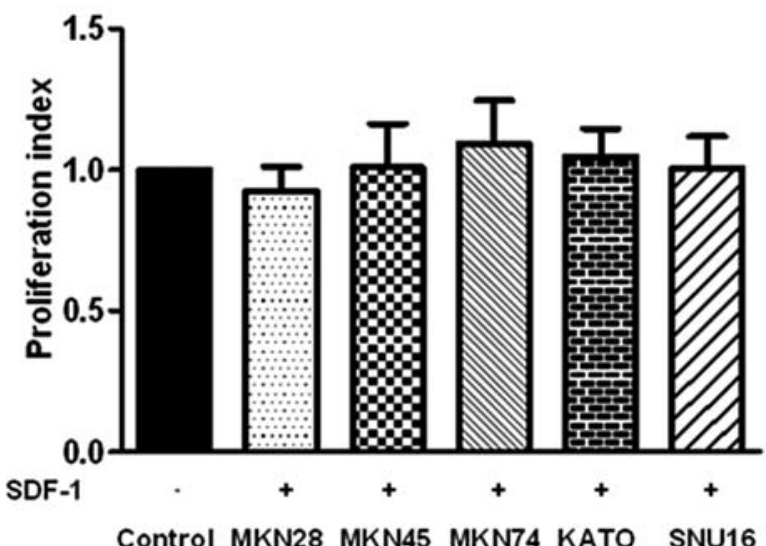

B $\bar{\alpha}$

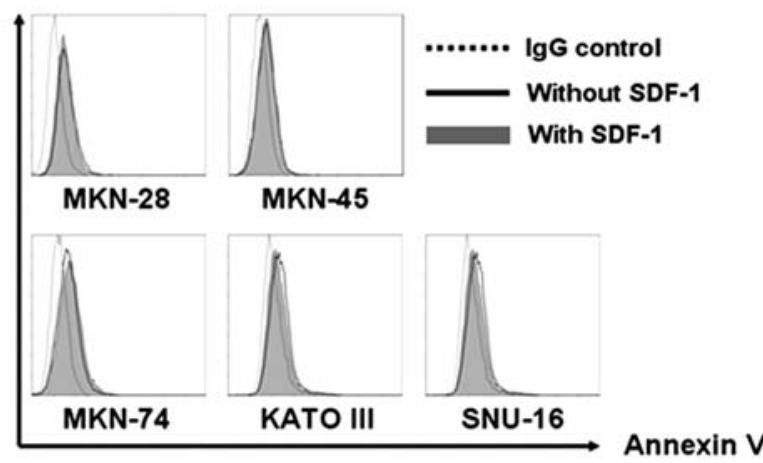

Figure 2. A. SDF-1 $\alpha$ does not enhance proliferation of MKN-28, MKN-45, MKN-74, KATO III, and SNU-16 cells. The cells were grown in serum-free media with or without SDF-1 $\alpha(100 \mathrm{ng} / \mathrm{ml})$ for $72 \mathrm{~h}$. Columns, mean of three separate experiments in triplicate wells; bars, SE. B, SDF-1 $\alpha$ does not protect cancer cells from serum deprivation-induced apoptosis. Each cell type was incubated in serum-free media with or without SDF-1 $\alpha(100 \mathrm{ng} / \mathrm{ml})$ for $24 \mathrm{~h}$. PI, propidium iodide. Data are representative of at least three independent experiments.

we analyzed the signaling pathways activated by CXCR4 in response to SDF-1 $\alpha$ treatment. To determine the effects of SDF- $1 \alpha$ on MAPK pathway activation, KATO III cells were treated with SDF-1 $\alpha$ and the phosphorylated forms of Erk1/2 MAPK were measured; phosphorylation of T202 and Y204 residues of Erk MAPK are closely related to the kinase activity of the protein. The phosphorylated forms of MAPK increased after treatment with SDF- $1 \alpha$ in KATO III cells (Fig. 3C). In addition, increased phosphorylation of MAPK was blocked by AMD3100 (Fig. 3D). To determine whether SDF- $1 \alpha$ activates the Stat 3 and Akt signaling pathways in KATO III cells, we measured the levels of phosphorylated Stat 3 and Akt after SDF- $1 \alpha$ treatment. SDF- $1 \alpha$ did not increase phosphorylation of Stat 3 at Y705 or Akt at S473 (Fig. 3C).

Correlation between CXCR4 expression in gastric cancer tissues and clinicopathological factors. Immunohistochemical staining of gastric cancer tissue sections revealed predominantly cytoplasmic CXCR4. Some membrane localized CXCR4 also was found. However, nuclear staining of CXCR4 was not observed. The respective expression rate for CXCR4 varied (no, 3.2\%; weak, 14.5\%; intermediate, $33.5 \%$; strong intensity, 48.9\%; Fig. 4A-D). There were no significant 
A

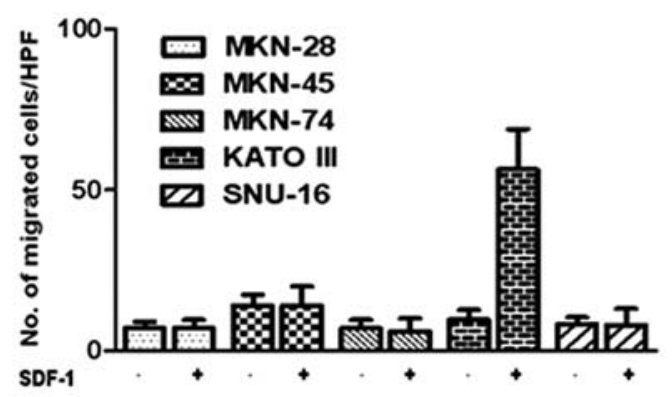

C

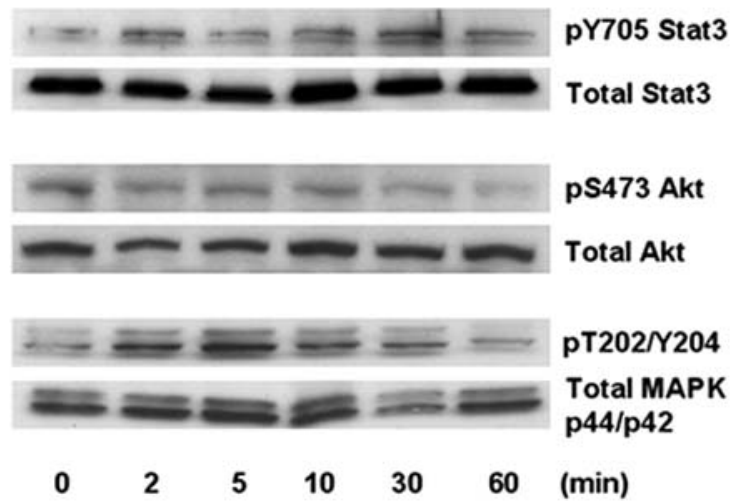

B

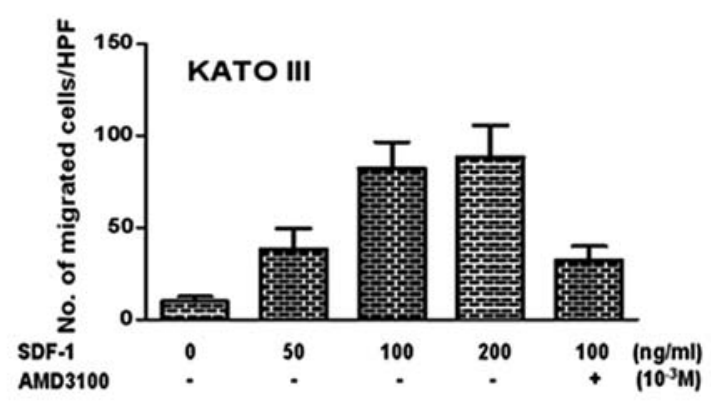

D

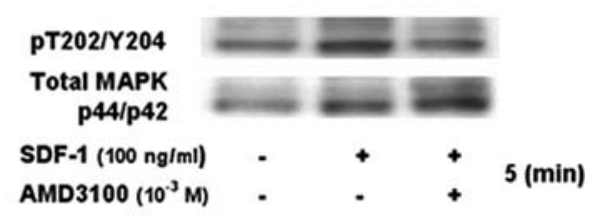

Figure 3. A, KATO III cells expressing membrane CXCR4 migrate toward the SDF-1 $\alpha$ gradient in a CXCR4-mediated manner. MKN-28, MKN-45, MKN-74, KATO III, and SNU-16 cells were grown in media containing $10 \%$ FBS, and $2.5 \times 10^{5}$ cells were then incubated in media without serum in the upper chamber of a 24-well Transwell containing a 4- $\mu \mathrm{m}$ microporous membrane. The lower chamber was treated with SDF-1 $\alpha$ (100 ng/ml) for $4 \mathrm{~h}$. B, KATO III cells were grown in media containing $10 \%$ FBS to $70 \%$ confluence, and $2.5 \times 10^{5}$ cells were then incubated in medium without serum in the upper chamber of a $24-$ well Transwell. The lower chamber was treated with the indicated concentrations of SDF-1 $\alpha$ for $4 \mathrm{~h}$. Migration was blocked by incubation with $10^{-3} \mathrm{M}$ AMD3100, a specific inhibitor of CXCR4 (last lane). Columns, mean of three independent experiments in triplicate wells; bars, SE. C, SDF-1 $\alpha$ phosphorylates MAPK, but not Stat3 and Akt, in KATO III cells expressing membrane CXCR4. KATO III cells were cultured to 50\% confluence. After serum starvation, the cells were stimulated with SDF-1 $\alpha(100 \mathrm{ng} / \mathrm{ml})$ for the indicated times. Total cell lysates were prepared and analyzed by Western blotting with the indicated antibodies. D, Phosphorylation of MAPK by SDF-1 $\alpha$ was blocked by AMD3100, a specific inhibitor of CXCR4. KATO III cells were preincubated with or without $10^{-3} \mathrm{M}$ AMD3100, and were then treated with or without $100 \mathrm{ng} / \mathrm{ml} \mathrm{SDF}-1 \alpha$ for $5 \mathrm{~min}$. Whole lysates were separated by SDS-PAGE, and phosphorylated MAPK was detected with anti-phospho-MAPK antibody. Data are representative of at least three independent experiments.

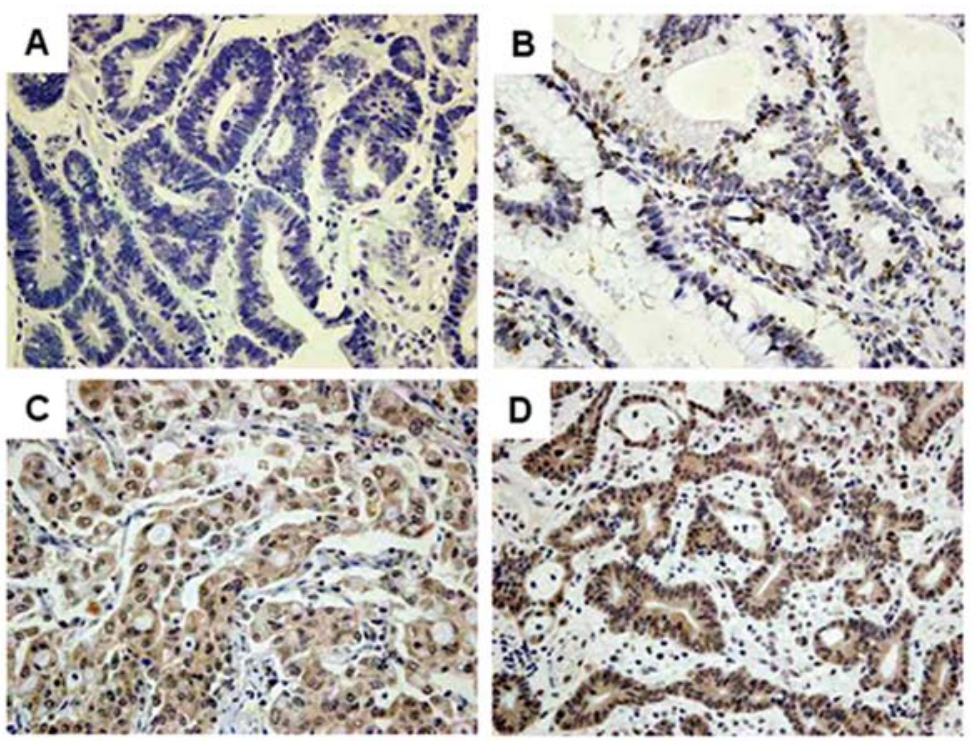

E

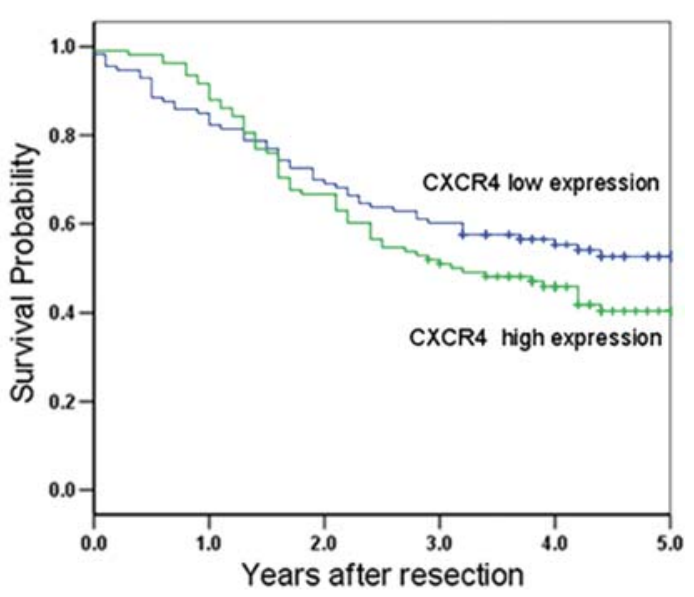

Figure 4. Representative photomicrographs of immunohistochemical staining for CXCR4 in human gastric cancer tissues. A, No staining intensity. B, Weak staining intensity. C, Intermediate staining intensity. D, Strong staining intensity (x200). E, Survival curves of 221 gastric cancer patients according to the CXCR4 expression. 
Table I. Clinicopathological features of patients with gastric carcinoma according to CXCR4 expression.

\begin{tabular}{|c|c|c|c|}
\hline & \multicolumn{2}{|c|}{ CXCR4 expression } & \multirow[b]{2}{*}{ P-value } \\
\hline & $\begin{array}{c}\text { Low } \\
(n=113)\end{array}$ & $\begin{array}{c}\text { High } \\
(n=108)\end{array}$ & \\
\hline Age (years) & $58.2 \pm 11.8$ & $58.6 \pm 10.7$ & 0.857 \\
\hline \multicolumn{4}{|l|}{ Gender } \\
\hline Female/male & $35 / 78$ & $31 / 77$ & 0.712 \\
\hline \multicolumn{4}{|l|}{ Depth of invasion } \\
\hline $\mathrm{T} 1, \mathrm{~T} 2$ & 91 & 75 & 0.057 \\
\hline $\mathrm{T} 3, \mathrm{~T} 4$ & 22 & 33 & \\
\hline \multicolumn{4}{|l|}{ Nodal involvement } \\
\hline Yes/no & $37 / 76$ & $51 / 57$ & 0.028 \\
\hline \multicolumn{4}{|l|}{ Stage } \\
\hline $\mathrm{I}, \mathrm{II}$ & 98 & 79 & 0.047 \\
\hline III, IV & 15 & 29 & \\
\hline \multicolumn{4}{|l|}{ Histology } \\
\hline Differentiated & 51 & 54 & 0.469 \\
\hline Undifferentiated & 62 & 54 & \\
\hline \multicolumn{4}{|l|}{ Tumor location } \\
\hline Upper & 4 & 8 & 0.303 \\
\hline Middle & 62 & 55 & \\
\hline Lower & 45 & 45 & \\
\hline Whole & 2 & 0 & \\
\hline \multicolumn{4}{|c|}{ Lymphatic invasion } \\
\hline Yes/no & $30 / 83$ & $21 / 87$ & 0.210 \\
\hline \multicolumn{4}{|l|}{ Venous invasion } \\
\hline Yes/no & $30 / 83$ & $22 / 86$ & 0.266 \\
\hline \multicolumn{4}{|l|}{ Tumor size $(\mathrm{cm})$} \\
\hline$\leq 5$ & 93 & 84 & 0.400 \\
\hline$>5$ & 20 & 24 & \\
\hline
\end{tabular}

differences in age, gender, histology, tumor location, lymphatic invasion, venous invasion, or proportion of tumor size $>5 \mathrm{~cm}$ between high CXCR4 expression and low CXCR4 expression groups. However, high CXCR4 expression tended to be associated with invasion depth of the tumor ( $T$ status; $\mathrm{P}=0.057$ ). Furthermore, high CXCR4 expression was significantly correlated with lymph node involvement $(\mathrm{N}$ status; $\mathrm{P}=0.028)$ and higher stage III/IV ( $\mathrm{P}=0.047$; Table I). Patients with high CXCR4 expression showed a reduced 5-year survival rate of $42.6 \%$ compared to $53.9 \%$ in patients with low CXCR4 expression, as depicted in the survival curve (log-rank test, $\mathrm{P}=0.1$; Fig. 4E).

\section{Discussion}

Increasing evidence suggests that epithelial tumor cells exploit several mechanisms including chemokine systems that normally regulate leukocyte trafficking and homing. The distinct pattern of chemokine receptor expression by tumor cells has a critical role in tumor biology. In particular, expression of CXCR4 is associated with more aggressive behaviors of various tumor cells in vivo and in vitro $(5,6,13)$. Regarding gastric cancer, however, the significance of CXCR4 has not been well-defined. Therefore, we investigated the expression and function of CXCR4 in gastric cancer cell lines in vitro, and attempted to correlate clinicopathological factors of gastric cancer with CXCR4 expression.

We found that MKN-28, MKN-45, MKN-74, and SNU16 cells contained CXCR4 transcripts and cytosolic CXCR4 protein, but did not express membrane CXCR4. However, membrane CXCR4 was identified in a small population of KATO III cells. The discrepancy between the presence of CXCR4 transcripts and proteins and the lack of membrane CXCR4 may occur for several reasons: instability of membrane CXCR4 expression has been noted in other cells, such as neuroblastoma cells (11); autocrine secretion of SDF-1 $\alpha$ may result in endocytosis and ubiquitin-mediated degradation of CXCR4 (14-16); and CXCR4 may be retained in the endoplasmic reticulum and fail to reach the cell surface (17).

CXCR4 may play an important role in the spread and progression of sarcomas, neuroblastomas, and melanomas, and cancers of the breast, ovary, bladder and cervix $(5,6)$. In this study, in vitro migration was SDF- $1 \alpha$-dependent in KATO III cells expressing membrane CXCR4. Moreover, the migration was inhibited by AMD3100, suggesting involvement of CXCR4 in SDF-1 $\alpha$-dependent migration. MKN-28, MKN-45, MKN-74, and SNU-16 cells, which did not express membrane CXCR4, did not show significant SDF- $1 \alpha$-induced migration in vitro. These observations suggest that membrane CXCR4 expression in cancer cells may affect biological behaviors such as tumor cell invasion and metastasis.

Several signaling molecules associated with the activation of CXCR 4 by SDF- $1 \alpha$ have been identified and include Stat3, Akt/PKB, Erk1/2 MAPK, PI3K, and NF-кB (18-23). We found that SDF-1 $\alpha$ treatment of KATO III cells promoted rapid phosphorylation of MAPK. When pretreated with AMD3100, SDF-1 $\alpha$-induced phosphorylation of MAPK was blocked. These findings suggest that SDF- $1 \alpha$-induced MAPK activation is downstream of CXCR4 and are consistent with the observation that AMD3100 prevented SDF- $1 \alpha$-stimulated migration of KATO III cells. However, SDF-1 $\alpha$ did not induce tyrosine phosphorylation of Stat 3 and Akt in KATO III cells, suggesting that SDF-1 $\alpha /$ CXCR4 signaling is cell type-specific.

Finally, we attempted to investigate and clarify the clinical implications of CXCR4 expression in gastric cancers. Currently, the clinical significance of CXCR4 expression in gastric cancer has not been well-defined and is controversial. Kwak et al investigated CXCR4 expression in gastric cancer by immunohistochemistry and found no significant clinical implications of CXCR4 expression in gastric cancer (24). However, they analyzed clinicopathological features primarily in CXCR-4-positive gastric cancers and showed very large differences between the expression levels of CXCR4 mRNA 
and protein. In contrast, other studies reported that CXCR4 expression in gastric cancers was correlated significantly with the development of peritoneal carcinomatosis in vivo and in vitro, suggesting that the CXCR4/SDF- $1 \alpha$ axis plays an important role in the development of peritoneal carcinomatosis and may be a potential therapeutic target (25-28). Zieker et al also revealed increased expression of CXCR4/SDF-1 $\alpha$ in primary gastric cancer tissue from patients with peritoneal carcinomatosis using gene expression profiling (29). In addition, Ishigami et al reported that SDF- $1 \alpha$ positivity was an independent prognostic factor for aggressive behavior in gastric cancer (30). Although they did not examine CXCR4 expression, the results of their study are in line with the view that SDF-1 $\alpha / \mathrm{CXCR} 4$ signaling may be a significant component of gastric cancer pathology.

In the present study, we investigated potential correlations between CXCR4 expression and the clinicopathological features in a large series of human gastric cancer tissues. High CXCR4 expression was significantly associated with lymph node metastases and higher stages III and IV. Furthermore, a trend for deep tumor invasion and shorter 5 -year survival was observed in patients with high CXCR4 expression. Thus, our results imply substantial effects of CXCR4 on the lymphatic dissemination of gastric cancer in vivo.

In conclusion, expression of functional CXCR4 by gastric cancer cells is associated with cancer cell migration in vitro, and high CXCR4 expression by gastric cancer tissues is significantly associated with lymph node metastases in patients with gastric cancer, suggesting that CXCR4 plays an important role during gastric cancer progression. Further investigations are needed to determine if CXCR4 could be a therapeutic target for gastric cancer.

\section{Acknowledgments}

This study was supported in part by grants from the Korea Research Foundation (KRF-2005-202-E00085).

\section{References}

1. Pelchen-Matthews A, Signoret N, Klasse PJ, Fraile-Ramos A and Marsh M: Chemokine receptor trafficking and viral replication. Immunol Rev 168: 33-49, 1999.

2. Zlotnik A and Yoshie O: Chemokines: a new classification system and their role in immunity. Immunity 12: 121-127, 2000 .

3. Nagasawa T, Hirota S, Tachibana K, Takakura N, Nishikawa S, Kitamura Y, Yoshida N, Kikutani H and Kishimoto T: Defects of B-cell lymphopoiesis and bone-marrow myelopoiesis in mice lacking the CXC chemokine PBSF/SDF-1. Nature 382: 635-638, 1996.

4. Retz MM, Sidhu SS, Blaveri E, Kerr SC, Dolganov GM, Lehmann J, Carroll P, Simko J, Waldman FM and Basbaum C: CXCR4 expression reflects tumor progression and regulates motility of bladder cancer cells. Int J Cancer 114: 182-189, 2005.

5. Burger JA and Kipps TJ: CXCR4: a key receptor in the crosstalk between tumor cells and their microenvironment. Blood 107: 1761-1767, 2006.

6. Ratajczak MZ, Zuba-Surma E, Kucia M, Reca R, Wojakowski W and Ratajczak J: The pleiotropic effects of the SDF-1-CXCR4 axis in organogenesis, regeneration and tumorigenesis. Leukemia 20: 1915-1924, 2006.

7. Arya M, Patel HR and Williamson M: Chemokines: key players in cancer. Curr Med Res Opin 19: 557-564, 2003
8. Muller A, Homey B, Soto H, Ge N, Catron D, Buchanan ME, McClanahan T, Murphy E, Yuan W, Wagner SN, Barrera JL, Mohar A, Verastegui E and Zlotnik A: Involvement of chemokine receptors in breast cancer metastasis. Nature 410: 50-56, 2001.

9. Koshiba T, Hosotani R, Miyamoto Y, Ida J, Tsuji S, Nakajima S, Kawaguchi M, Kobayashi H, Doi R, Hori T, Fujii N and Imamura M: Expression of stromal cell-derived factor 1 and CXCR4 ligand receptor system in pancreatic cancer: a possible role for tumor progression. Clin Cancer Res 6: 3530-3535, 2000.

10. Hartmann TN, Burger JA, Glodek A, Fujii N and Burger M: CXCR4 chemokine receptor and integrin signaling co-operate in mediating adhesion and chemoresistance in small cell lung cancer (SCLC) cells. Oncogene 24: 4462-4471, 2005.

11. Geminder H, Sagi-Assif O, Goldberg L, Meshel T, Rechavi G, Witz IP and Ben-Baruch A: A possible role for CXCR4 and its ligand, the CXC chemokine stromal cell-derived factor-1, in the development of bone marrow metastases in neuroblastoma. J Immunol 167: 4747-4757, 2001.

12. Japanese Gastric Cancer Association: Japanese Classification of Gastric Carcinoma. 2nd English edition. Gastric Cancer 1: 10-24, 1998.

13. Kucia M, Jankowski K, Reca R, Wysoczynski M, Bandura L, Allendorf DJ, Zhang J, Ratajczak J and Ratajczak MZ: CXCR4SDF-1 signalling, locomotion, chemotaxis and adhesion. J Mol Histol 35: 233-245, 2004.

14. Cheng ZJ, Zhao J, Sun Y, Hu W, Wu YL, Cen B, Wu GX and Pei G: $\beta$-Arrestin differentially regulates the chemokine receptor CXCR4-mediated signaling and receptor internalization, and this implicates multiple interaction sites between $B$-arrestin and CXCR4. J Biol Chem 275: 2479-2485, 2000.

15. Tarasova NI, Stauber RH and Michejda CJ: Spontaneous and ligand-induced trafficking of CXC-chemokine receptor 4. J Biol Chem 273: 15883-15886, 1998.

16. Marchese A and Benovic JL: Agonist-promoted ubiquitination of the $\mathrm{G}$ protein-coupled receptor CXCR4 mediates lysosomal sorting. J Biol Chem 276: 45509-45512, 2001.

17. Zeelenberg IS, Ruuls-van Stalle L and Roos E: Retention of CXCR4 in the endoplasmic reticulum blocks dissemination of a T cell hybridoma. J Clin Invest 108: 269-277, 2001.

18. Ahr B, Denizot M, Robert-Hebmann V, Brelot A and BiardPiechaczyk M: Identification of the cytoplasmic domains of CXCR4 involved in Jak2 and STAT3 phosphorylation. J Biol Chem 280: 6692-6700, 2005.

19. Lataillade JJ, Clay D, Bourin P, Herodin F, Dupuy C, Jasmin C and Bousse-Kerdiles MC: Stromal cell-derived factor 1 regulates primitive hematopoiesis by suppressing apoptosis and by promoting $\mathrm{G}(0) / \mathrm{G}(1)$ transition in $\mathrm{CD} 34(+)$ cells: evidence for an autocrine/paracrine mechanism. Blood 99: 1117-1129, 2002.

20. Ganju RK, Brubaker SA, Meyer J, Dutt P, Yang Y, Qin S, Newman W and Groopman JE: The $\alpha$-chemokine, stromal cellderived factor-1, binds to the transmembrane G-protein-coupled CXCR-4 receptor and activates multiple signal transduction pathways. J Biol Chem 273: 23169-23175, 1998.

21. Oh JW, Drabik K, Kutsch O, Choi C, Tousson A and Benveniste EN: CXC chemokine receptor 4 expression and function in human astroglioma cells. J Immunol 166: 2695-2704, 2001.

22. Sotsios Y, Whittaker GC, Westwick J and Ward SG: The CXC chemokine stromal cell-derived factor activates a Gi-coupled phosphoinositide 3-kinase in T lymphocytes. J Immunol 163: 5954-5963, 1999.

23. Han Y, He T, Huang DR, Pardo CA and Ransohoff RM: TNF-mediates SDF-1-induced NF-B activation and cytotoxic effects in primary astrocytes. J Clin Invest 108: 425-435, 2001.

24. Kwak MK, Hur K, Park DJ, Lee HJ, Lee HS, Kim WH, Lee KU, Choe KJ and Yang HK: Expression of chemokine receptors in human gastric cancer. Tumour Biol 26: 65-70, 2005.

25. Yasumoto K, Koizumi K, Kawashima A, Saitoh Y, Arita Y, Shinohara K, Minami T, Nakayama T, Sakurai H, Takahashi Y, Yoshie O and Saiki I: Role of the CXCL12/CXCR4 axis in peritoneal carcinomatosis of gastric cancer. Cancer Res 66: 2181-2187, 2006.

26. Ding YL, Zhang JL, Tang SF, Fu QY and Li ZT: Effect of chemokine stromal cell derived factor- 1 and its receptor CXCR4 on the peritoneal carcinometastasis of gastric cancer. Zhonghua Yi Xue Za Zhi 88: 202-205, 2008. 
27. Hashimoto I, Koizumi K, Tatematsu M, Minami T, Cho S, Takeno N, Nakashima A, Sakurai H, Saito S, Tsukada K and Saiki I: Blocking on the CXCR4/mTOR signalling pathway induces the anti-metastatic properties and autophagic cell death in peritoneal disseminated gastric cancer cells. Eur J Cancer 44: 1022-1029, 2008.

28. Iwanaga T, Iwasaki $Y$, Ohashi $M$, Nunobe $S$ and Iwagami S: Establishment of a CXCR4-expressing gastric cancer cell line in nude mice and the effect of AMD 3100 on tumor regression. Gan To Kagaku Ryoho 34: 1917-1919, 2007.
29. Zieker D, Königsrainer I, Traub F, Nieselt K, Knapp B, Schillinger C, Stirnkorb C, Fend F, Northoff H, Kupka S, Brücher BL and Königsrainer A: PGK1 a potential marker for peritoneal dissemination in gastric cancer. Cell Physiol Biochem 21: 429-436, 2008.

30. Ishigami S, Natsugoe $S$, Okumura $H$, Matsumoto $M$, Nakajo A, Uenosono Y, Arigami T, Uchikado Y, Setoyama T, Arima H, Hokita $S$ and Aikou T: Clinical implication of CXCL12 expression in gastric cancer. Ann Surg Oncol 14: 3154-3158, 2007. 